\title{
Retenção escolar: uma análise no curso de Licenciatura em Matemática do IFCE
}

\author{
School retention: an analysis in the IFCE Mathematics Licensing \\ course
}

Retención escolar: análisis del curso de Licencia de Matemáticas IFCE

Denise de Araújo Silva Holandaㄹ; Heloisa Beatriz Cordeiro Moreira²

\section{RESUMO}

A retenção é um fenômeno requer atenção uma vez que interfere no processo ensino aprendizagem e na conclusão dos cursos. A presente pesquisa tem como objetivo analisar a retenção no curso de Licenciatura em Matemática do Instituto Federal de Educação Ciência e Tecnologia do Ceará (IFCE) Campus Cedro. A pesquisa foi de base qualitativa, cujo percurso metodológico incluiu pesquisa bibliográfica, documental e de campo. Adotou-se como técnica de coleta de dados o questionário eletrônico, articulado aos referenciais teóricos priorizados nesse estudo. A amostra da pesquisa foi composta de 43 discentes retidos do curso em análise de um total de 183 matriculados no curso. Os dados após coleta, foram ordenados e classificados através de gráficos, quadros e tabelas. Concluiu-se que a retenção se apresenta como uma problemática complexa, não sendo possível apontar um único fator determinante para ocorrência do fenômeno, tendo origem nos diversos fatores individuais dos estudantes, internos e externos ao ambiente institucional, sendo necessário a elaboração de estratégias para o desenvolvimento de ações para prevenção e acompanhamento dos estudantes retidos.

Palavras-chave: Educação Profissional; Retenção Escolar; Institutos Federais.

\begin{abstract}
The retention is a phenomenon that demands attention because it interferes as about teaching-learning process as the completed courses. This research aims analyzing the retention into Mathematics Degree course in the Federal Institute of Education Science and Technology from Ceará (IFCE) campus Cedro. The research showed a qualitative basis which by the way its methodological path included bibliographic, documentary and field research. The electronic questionnaire considered itself as the data collection technique, associated with the theoretical frameworks prioritized in this study. The research sample consisted of 43 students retained from the analyzed course out of a total of 183 enrolled in the course. The data after collection were ordered and classified using graphs, charts and tables. It was concluded that retention presents itself as a complex problem, so it is not possible to point out a single determining factor for the occurrence of the phenomenon, originating in the various individual factors of students, internal and external to the institutional environment, requiring elaboration of strategies for the development of actions for the purpose of prevention and monitoring of detained students.
\end{abstract}

Keywords: Professional education; School Retention; Federal Institutes.

\footnotetext{
${ }^{1}$ Bacharel em Serviço Social, Especialista em Serviço Social, Direitos Sociais e o Trabalho em Comunidade, Licenciada em Ciências com Habilitação em Biologia, Especialista em Educação Ambiental e Mestranda em Educação Profissional e Tecnológica (ProfEPT). Assistente Social no Instituto Federal de Educação, Ciência e Tecnologia do Ceará (IFCE), Cedro/CE - Brasil. E-mail: denise.holanda@ifce.edu.br

2 Doutora em Engenharia Civil, Mestra em Engenharia Mecânica, Engenheira de segurança do Trabalho, Graduada em Engenharia Química e Graduação em Formação Pedagógica para Educação Profissional. Docente do Instituto Federal de Educação, Ciência e Tecnologia do Ceará (IFCE) e do Mestrado em Educação Profissional e Tecnológica (ProfEPT), Fortaleza/CE - Brasil. E-mail: heloisa.beatriz@ifce.edu.br
} 


\section{RESUMEN}

La retención es un fenómeno que requiere atención ya que interfiere en el proceso de enseñanza-aprendizaje y en la finalización de los cursos. Esta investigación tiene como objetivo analizar la retención en el curso de Licenciatura en Matemáticas del Instituto Federal de Educación, Ciencia y Tecnología de Ceará (IFCE) Campus Cedro. La investigación fue de base cualitativa, cuyo enfoque metodológico incluyó la investigación bibliográfica, documental y de campo. Se adoptó como técnica de recolección de datos el cuestionario electrónico, vinculado a los referenciales teóricos priorizados en este estudio. La muestra de la investigación fue compuesta de 43 estudiantes retenidos del curso en análisis de un total de 183 matriculados en el curso. Los datos después de la recolección fueran ordenados y clasificados a través de gráficos, cuadros y tablas. Se concluyó que la retención se presenta como un problema complejo, no siendo posible señalar un solo factor determinante para la ocurrencia del fenómeno, teniendo origen en los diversos factores individuales de los estudiantes, internos y externos al ambiente institucional, siendo necesario la elaboración de estrategias para el desarrollo de acciones de prevención y seguimiento de estudiantes retenidos.

Palabras clave: Educación profesional; Retención escolar; Institutos Federales.

\section{INTRODUÇÃO}

A expansão e a interiorização dos institutos, ampliando a oferta de educação profissional e acesso ao ensino, aponta para um desafio de garantir a permanência dos alunos nessas instituições. Assim, surge uma preocupação com o papel da escola na sociedade, no plano Educacional, inclusive das escolas públicas, cada vez mais reforçado pelos estudos acerca das problemáticas que interferem no processo ensino-aprendizagem, o qual provoca a saída da escola (SANTOS; MEDEIROS; VALLERIUS, 2017).

Neste sentido, verifica-se que apesar do aumento do número de vagas e de maior garantia do acesso ao ensino, tem-se se destacado as problemáticas no cenário educacional: os índices elevados de evasão $^{3}$ associados ao de retenção ${ }^{4}$, inclusive nos Institutos Federais de Educação Ciência e Tecnologia, segundo a ferramenta de compilação de dados do ensino, o IFCE em Números ${ }^{5}$. De acordo com Dore e Luscher (2011, p.775), a evasão tem sido associada a várias situações, referindose "à retenção e repetência do aluno na escola; à saída do aluno da instituição; à saída do aluno do sistema de ensino; à não conclusão de um determinado nível de ensino; ao abandono da escola".

Assim, foi publicado no ano de 2014 pelo Ministério da Educação o "Documento Orientador para a Superação da Evasão e Retenção na Rede Federal de Educação Profissional, Científica e Tecnológica". O referido documento contém instruções para a criação dos planos estratégicos institucionais para as unidades dos Institutos Federais.

Com base nesse documento orientador, o Instituto Federal de Educação, Ciência e Tecnologia do Ceará (IFCE) publicou seu plano estratégico em 2017, intitulado "Plano Estratégico para Permanência e Êxito dos Estudantes do IFCE" com vigência de 2017-2024. Assim, mediante, o plano apresenta a problemática da evasão e retenção na instituição nos semestres de 2009.1 até 2017.2, visualizando

\footnotetext{
${ }^{3}$ A evasão é a interrupção no ciclo de estudos, provocado pela saída dos estudantes da instituição, sem concluir o curso, trazendo consequências graves de ordem social, acadêmico e econômico (GAIOSO, 2005).

${ }^{4} A$ retenção se refere ao tempo prolongado de permanência do estudante na instituição escolar, ultrapassando o tempo previsto na matriz curricular para conclusão do curso (BRASIL, 1996).

${ }^{5}$ O IFCE em Números é um local único de divulgação dos dados quantitativos relativos às atividades de ensino da instituição, com base nos dados do sistema acadêmico da instituição (IFCE, 2017). Ferramenta disponível em: http://ifceemenumeros.ifce.edu.br .
} 
que nos cursos do IFCE há um grande contingente de estudantes que se evadiram ou estão retidos, como é o exemplo dos cursos superiores que apresentaram o índice de $9,96 \%{ }^{6}$ de taxa de conclusão (IFCE, 2017). Essa realidade sugere que a retenção merece destaque nas investigações no âmbito da educação profissional e dos gestores das instituições, tendo em vista que esse fenômeno está intimamente ligado à evasão escolar.

Destacamos o campus Cedro, dentre os campi do IFCE, com um número expressivo de 1231 estudantes matriculados ${ }^{7}$, tendo um grande potencial de formação de alunos na região. No entanto, no ano de 2019 , as taxas de retenção ${ }^{8}$ nos cursos superiores atingiram $17,3 \%$ no mesmo ano. Esses dados representam o percentual de alunos que não concluíram seus cursos no tempo previsto pela instituição. Tal problema afeta várias modalidades de ensino, que contam com dificuldades para reduzir a incidência da evasão escolar e suas negativas consequências. Logo, estas implicações podem ser observadas de modo especial na formação e capacitação dos estudantes, pois há uma interrupção do avanço do discente nas etapas de formação acadêmica.

Diante dessa problemática, esta pesquisa torna-se relevante como instrumento para análise da temática, sendo possível desvendar o que se relaciona com o contexto do objeto de estudo e suas causas nos cursos. Silva, Rodrigues e Brito (2014), comentam que são obstáculos de diversas ordens, que surgem ao longo do processo de formação acadêmica, os quais podem resultar na retenção ou numa evasão futura. Por essa razão se torna importante compreender a retenção nos cursos do IFCE campus Cedro, para que se possa implementar ações que busquem formas de minimizar a ocorrência desse fenômeno, bem como contribuir para a permanência e êxito dos estudantes na instituição.

Face ao contexto, partiu-se dos seguintes questionamentos: qual o perfil do estudante retido? Quais os fatores associados à retenção? A partir das indagações apresentadas, delineou-se como objetivo geral: analisar a retenção escolar no curso licenciatura em Matemática do Instituto Federal de Educação Ciência e Tecnologia IFCE Campus Cedro.

\section{RETENÇÃO ESCOLAR NO CONTEXTO DA EDUCAÇÃO PROFISSIONAL E TECNOLÓGICA}

Nos estudos brasileiros o termo retenção tem sido mais utilizado no Ensino Superior, e está associado a permanência prolongada, no qual o discente está ultrapassando o tempo/período para conclusão de seus cursos. Dessa forma, tem-se uma representação negativa da situação de retenção, apresentando-se como uma problemática presente nos ambientes escolares, sendo considerada um fenômeno complexo, pois aponta para o processo ensino-aprendizagem, e que atinge várias instituições e modalidades de ensino no país (MARTINHO et al., 2019).

Neste sentido, a evasão e retenção vem sendo debatida a partir da década de 1990, onde é dado destaque ao relatório de dados disponibilizado pela Comissão Especial para o Estudo da Evasão nas

\footnotetext{
${ }^{6}$ Dados coletados no IFCE números nos semestres de 2009.1 até 2017.2.

7 Dado coletado no Q - Acadêmico do IFCE campus Cedro no período dezembro de 2020.

8 Dados coletados da Plataforma Nilo Peçanha, ano base 2019. Essa plataforma é um ambiente virtual de coleta, validação e disseminação das estatísticas oficiais da Rede Federal de Educação, Ciência e Tecnologia, disponível em http://plataformanilopecanha.mec.gov.br/ .
} 
Universidades Brasileiras (1996), criado pelo Ministério da Educação. O estudo trouxe dados sobre o desempenho das universidades públicas brasileiras em relação aos índices de diplomação, retenção e evasão dos estudantes de seus cursos de graduação (BRASIL, 1996).

Tendo como referência os estudos pioneiros da comissão, que adotamos o conceito de retenção, que é a questão do tempo prolongado de permanência do estudante para conclusão do curso, tendo em vista que o tempo previsto de sua saída tenha terminado, e ainda continua matriculado.

Os estudos da Comissão Especial foram pioneiros em identificar as causas da evasão e retenção, e ainda apontaram as formas de reduzir os altos índices nas instituições públicas de Ensino Superior e "configurou-se em uma das primeiras iniciativas de uniformização do processo de coleta e de tratamentos de dados em âmbito nacional" (EVANGELISTA, 2020, p.3). Com base neste estudo, a evasão estava em aproximadamente $50 \%$ e a diplomação com baixo percentual, e a retenção maior que $10 \%$, sendo importante salientar que a Comissão considera que se uma instituição apresenta uma taxa maior que $10 \%$ ou taxas de diplomação abaixo da média, merecem análise cuidadosa por parte das instituições.

Frente a essa problemática, Silva, Rodrigues e Brito (2014) comentam que os estudantes que ingressam na universidade, não conseguem concluir no tempo previsto, havendo fatores que impedem esse fluxo contínuo, sendo a retenção, um dos principais precedentes para uma futura evasão do estudante.

Desse modo, deve ser considerada a íntima relação entre o fenômeno da retenção e a evasão, pois estes ocorrem no mesmo ambiente escolar, podendo envolver os mesmos fatores causais e que afetam negativamente as instituições escolares. Segundo Evangelista (2020, p.5-6), são "problemáticas equivalentes, visto que um fator causal de retenção, se não percebido e devidamente considerado pelo gestor educacional, pode tornar-se causa de elevação nos índices de evasão".

No âmbito da Educação Profissional e Tecnológica (EPT), a preocupação com o tema da evasão e retenção entrou em cena na expansão dos Institutos Federais (IF's) por todo o país. Vale salientar que através da lei no 11.892/2008 é instituída a Rede Federal de Educação Profissional, Científica e Tecnológica e cria os Institutos Federais de Educação, Ciência e Tecnologia, sendo instituições de educação superior, básica e profissional, pluricurriculares e multicampi, especializados na oferta de educação profissional e tecnológica nas diferentes modalidades de ensino, com base na conjugação de conhecimentos técnicos e tecnológicos com as suas práticas pedagógicas (BRASIL, 2008).

Dessa forma, a expansão do IF's, visando ampliar o atendimento em educação profissional, apontou para o desafio da permanência dos estudantes nos cursos ofertados pelos Institutos e as dificuldades decorrentes desse processo. A retenção escolar, é uma dessas problemáticas, sendo necessário a criação de estratégias para minimizar os índices, a fim de não ocorrer a saída definitiva do estudante da escola.

Diante dessa problemática, no período de 2011 a 2012 o Tribunal de Contas da União, mediante o Relatório Anual de Atividades (BRASIL, 2012), elaborado através do levantamento de dados retirados do SISTEC (Sistema Nacional de Informações da Educação Profissional e Tecnológica), recomendou ao Ministério da Educação (MEC) que medidas sejam tomadas para conter a evasão e retenção escolar nos Institutos Federais. Esse relatório trouxe a premissa de que aqueles alunos com problemas de retenção e com maior nível de atraso, relacionado à idade/série, são os mais propensos a evadir do sistema escolar (OLIVEIRA, 2019). 
Perante essa realidade, o MEC lança em 2014 o documento orientador para a superação da evasão e retenção na Rede Federal, através da Secretaria de Educação Profissional e Tecnológica (SETEC), o referido documento trouxe a constatação de que seria necessário dar em enfoque às taxas de evasão e de retenção nos cursos ofertados pela Rede Federal, ao demonstrar o número de alunos em seus ciclos de matrículas de 2004 a 2011. Como exemplo, temos o caso dos cursos técnicos integrados para estudantes em idade própria, onde a taxa de evasão apresentava-se em 6,4\%, a de retenção em $44,42 \%$ e por último a de conclusão com apenas $46,8 \%$ (BRASIL, 2014).

Neste sentido, Lima (2018) também destaca a retenção dos estudantes matriculados nos cursos técnicos integrados ao ensino médio do Instituto Federal de São Paulo (IFSP) no Campus São Paulo no período de 2014 a 2017, revelando que os índices de retenção nas turmas ingressantes, estava vinte por cento acima das turmas concluintes, demonstrando ser um problema para os estudantes prosseguirem seus estudos.

É possível observar que a retenção está inserida no contexto social da vida dos estudantes dos IFs, pois muitos são os fatores que interferem no processo formativo, sendo necessário ampliar as possibilidades de permanência e êxito, implementando políticas através de ações e programas para reflexão e diagnóstico das causas de evasão e retenção, e suas possíveis formas de enfrentamento a essas problemáticas.

\section{BREVE CONSIDERAÇÕES SOBRE OS FATORES DETERMINANTES DA RETENÇÃO ESCOLAR}

O processo de retenção escolar envolve uma diversidade de elementos, sendo necessária a compreensão de que não há um único fator ou causa responsável para a ocorrência do fenômeno, pois, são inúmeros os determinantes que interferem no processo ensino-aprendizagem dos estudantes nas instituições escolares, inclusive nas Instituições da Rede Federal de Educação Profissional, Científica e Tecnológica.

Os fatores e causas da retenção escolar estão intrinsecamente ligados aos da evasão. Sobre isso, Dore e Lüscher (2011) salientam a dificuldade de se identificar as prováveis causas da evasão, pois são influenciados por diversos fatores e causas. Como também pelo fato de que a realidade é dinâmica e são vários os determinantes, políticos, sociais, econômicos e culturais que incidem na realidade do aluno. Rosa (2019, p.65) coaduna ao afirmar que "levando-se em consideração todos os fatores e causas que podem estar relacionados tanto ao estudante, quanto à família, à escola, à comunidade em que vive e até mesmo ao professor."

Daitx, Loguercio e Strack (2016) apontaram como causa da retenção, a reprovação dos estudantes nas disciplinas, em um curso de Licenciatura em Química noturno, do Instituto de Química da Universidade Federal do Rio Grande do Sul, evidenciando que no período de 2009 a 2013, a retenção atingiu cerca de $65 \%$ dos alunos, e que desse total, cerca de $60 \%$ estão retidos na primeira ou segunda etapa do curso, e na maioria dos casos não conseguindo retornar a etapa, prolongando assim o tempo para se graduar.

Outro estudo que se destaca é o de Pereira (2013), por trazer a reflexão sobre a retenção discente nos cursos superiores de graduação na Universidade Federal do Espírito Santos (UFES), tendo como objetivos principais a identificação de fatores associados à retenção dos estudantes dos cursos em análise e ainda a proposição de ações de intervenção na problemática. O autor constatou que os 
principais fatores para ocorrência da retenção foram coeficiente de rendimento acumulado, número de reprovações, relação candidato/vaga do vestibular, área do conhecimento, desempenho na segunda etapa do vestibular e trancamento de curso.

Lima (2018) apresentou outra perspectiva de análise da retenção, através de um estudo preliminar do perfil dos estudantes nos cursos técnicos integrados ao ensino médio do Instituto Federal de Educação, Ciência e Tecnologia campus São Paulo. Este estudo se baseou nos dados disponibilizados pelo sistema de matrícula no período de 2014 a 2017, sendo mensurado que em geral os estudantes são oriundos de escola pública estadual e/ou municipal, bem como, são predominantemente, negros e/ou pardos, principalmente no ano de 2016. Ainda concluiu que o conhecimento e a compreensão do perfil desses estudantes contribuem para se pensar estratégias de ação para minimizar a retenção.

Ainda considerando os fatores causais da retenção, Rios et al. (2018) analisaram as ocorrências de evasão, retenção e colação de grau de estudantes de uma instituição federal de ensino em Florianópolis, multicampi, formada por dez unidades acadêmico-administrativas. Para coleta de dados desse estudo, foram aplicados questionários semiestruturados aos estudantes beneficiários do plano de permanência da instituição no período de 2009-2015. Os resultados relacionados a retenção foram adotados pelos autores nas categorias, reprovação, dificuldade de aprendizagem e trancamento do curso, sendo os percentuais mais elevados os da reprovação, visto que $67,40 \%$ possuem algum tipo de reprovação (nota, frequência e ambas), tendo sido apresentados em maior percentual as metodologias dos professores como motivações para reprovação. Enquanto nas outras categorias analisadas, os estudantes afirmaram em sua maioria, não possuírem dificuldades de aprendizagem e não ter realizado trancamento do curso em seu percurso acadêmico.

Nesse contexto da reprovação escolar, Melo e Saldanha (2020) em sua pesquisa no IFCE, campus Quixadá, com o curso de licenciatura em química, analisou a retenção ocasionada por reprovações, identificando os principais fatores influenciadores, a falta de conhecimentos prévios e de identidade com o curso. Dessa forma, diante dos resultados encontrados pelos autores, é dado ênfase na dificuldade na aprendizagem dos conteúdos traz como consequência, a desmotivação do aluno na sua trajetória acadêmica, sendo necessárias ações de intervenção das instituições federais para garantia do êxito estudantil e prevenir a saída definitiva do estudante da instituição.

O estudo realizado por Evangelista (2020) identificou aspectos importantes no processo de retenção nos cursos superiores de graduação do IFCE campus Maracanaú. A autora obteve em seus resultados, os fatores mais relevantes associados à ocorrência da retenção, tais como: dificuldades na conciliação do horário das disciplinas com o trabalho, dificuldades para se dedicar aos estudos; curso ofertado em horário incompatível.

Face ao exposto nesse tópico, foi possível perceber que há uma relação de causalidade entre os fatores, sendo eventos que se interrelacionam, não nos permitindo apontar um único elemento para a ocorrência da retenção escolar, compondo o fenômeno como complexo e multifacetado, pois se relaciona com a aprendizagem dos estudantes, com a forma que se relacionam com o saber, a sua própria particularidade e singularidade de inserção nas relações sociais. 


\section{PROCEDIMENTOS METODOLÓGICOS}

A presente pesquisa utilizou-se de abordagem qualitativa, por nos permitir uma aproximação maior com a realidade dos sujeitos, inferindo dimensões subjetivas que se configuram como significativas para compreensão do tema estudado. De acordo com Minayo (2009, p.21), a pesquisa qualitativa "responde a questões particulares [...] ela trabalha com o universo de significados, dos motivos, das aspirações, das crenças, dos valores, e das atitudes".

Em razão dos objetivos propostos, os tipos de pesquisa abordados neste trabalho foram a pesquisa bibliográfica, documental e de campo. Na pesquisa bibliográfica adotou-se referenciais teóricos de autores que tratam da temática abordada em artigos, livros, dissertações e teses. Já na pesquisa documental foram analisados documentos oficiais, públicos de abrangência nacional, regional e local, ligados a temática de retenção escolar e o banco de dados presente no Sistema de Registro Acadêmico (Q-acadêmico) na Instituição pesquisada.

E a pesquisa de campo possibilitou a obtenção de dados da realidade investigada, realizada por meio da aplicação de um questionário eletrônico enviado por e-mail aos participantes da pesquisa, com o intuito de obter as respostas que subsidiem o conhecimento da população pesquisada para compreensão do fenômeno da retenção.

Dessa forma, a pesquisa foi realizada no Instituto Federal de Educação, Ciência e Tecnologia do Ceará - IFCE Campus Cedro. Sendo uma instituição de grande relevância para o desenvolvimento econômico, social e cultural do município e da microrregião, por desenvolver de forma articulada as atividades de ensino, pesquisa e extensão. Atualmente a instituição oferta para a população, os cursos técnicos em Eletrotécnica e Mecânica Industrial, técnicos integrados em Eletrotécnica, Informática e Mecânica Industrial, além dos cursos superiores de Tecnologia em Mecatrônica Industrial, Licenciatura em Matemática, Licenciatura em Física e Sistemas da Informação.

Os participantes da pesquisa compreenderam os estudantes do curso de Licenciatura em Matemática do IFCE campus Cedro, o qual estavam em situação de retenção, ou seja, ultrapassando o limite de conclusão dos cursos previstos pela instituição. Salienta-se que a escolha do curso se deu pelos índices elevados de retenção no semestre letivo $2019.1^{9}$. Não sendo considerados nesta pesquisa, os cursos de graduação de criação recente por não propiciar a amplitude dos dados na questão temporal.

Em relação à seleção dos estudantes, o estudo foi realizado mediante os dados obtidos junto ao Sistema de Registro Acadêmico (Q-acadêmico), no período de outubro a novembro de 2020, sendo adotados três procedimentos. Primeiro, gerou-se os relatórios dos estudantes regularmente matriculados no semestre letivo 2020.1 e segundo, identificou-se os alunos ingressantes em determinado semestre até o prazo previsto de conclusão, conforme as matrizes curriculares de cada curso. E o terceiro procedimento, foi a verificação do semestre de ingresso que o aluno seria considerado retido, visto que estes estudantes se mantinham matriculados ultrapassando o tempo de integralização do curso, assim estabeleceu-se como limite de conclusão o semestre 2020.1 para o curso analisado, como apresentado no Quadro 1.

\footnotetext{
${ }^{9}$ Dado coletado na plataforma do IFCE números com referência ao semestre letivo 2019.1
} 
Quadro 1- Curso e semestre limite considerado para a amostra

\begin{tabular}{|c|c|c|c|c|c|}
\hline Curso & $\begin{array}{c}\text { Duração } \\
\text { do curso }\end{array}$ & $\begin{array}{c}\text { Quantidade } \\
\text { de } \\
\text { Semestres }\end{array}$ & $\begin{array}{c}\text { Semestre } \\
\text { máximo de } \\
\text { ingresso }\end{array}$ & $\begin{array}{c}\text { Conclusão } \\
\text { do curso } \\
\text { Prevista }\end{array}$ & $\begin{array}{c}\text { Semestre } \\
\text { base para } \\
\text { retenção }\end{array}$ \\
\hline $\begin{array}{c}\text { Licenciatura em } \\
\text { Matemática }\end{array}$ & 4 anos & 8 & 2016.2 & 2020.1 & 2016.1 \\
\hline
\end{tabular}

Fonte: Q - Acadêmico, 2020.

Neste sentido, conforme exposto no quadro acima, consideramos o semestre letivo 2016.2 para o período de previsão de conclusão regular em 2020.1. Assim, os estudantes com matrículas ingressantes a partir e abaixo de 2016.1 que não estavam na condição de formados/concluídos foram considerados em situação de retenção escolar, sendo a amostra para fins dessa pesquisa o quantitativo de 43 estudantes retidos. Esse quantitativo de discentes retidos perfaz o público selecionado dentre o total de 183 alunos matriculados no curso.

Dessa forma, foi aplicado questionário eletrônico aos participantes da pesquisa, elaborado pela autora no serviço gratuito de formulários online (Google Forms), compostos por questões abertas e de múltipla escolha. Os participantes receberam os questionários via endereço eletrônico (e-mail) e retornaram pela mesma via de comunicação.

Vale salientar que coleta de dados somente ocorreu após aprovação junto ao Comitê de Ética e Pesquisa do IFCE, sendo os questionários encaminhados individualmente para os e-mails dos participantes da pesquisa, e anexo ao questionário seguiu-se o Termo de Consentimento Livre e Esclarecido (TCLE). O referido questionário foi composto por duas partes, a primeira refere-se ao perfil dos estudantes (gênero, idade, raça e renda mensal familiar). A segunda parte, consiste nas principais causas da retenção, motivo para não conclusão dos cursos e as dificuldades para conclusão. Em relação a devolutiva dos questionários eletrônicos por parte dos sujeitos pesquisados, tivemos uma taxa de devolução total de $86,04 \%$ (37 respondentes) dos estudantes retidos do curso de Licenciatura em Matemática.

O processo de avaliação dos dados coletados nesta pesquisa utilizou a análise qualitativa proposta por Minayo (2012), no qual é possível descobrir seus códigos sociais, mediante as informações, falas e símbolos expressos na realidade social investigada, vinculando-se pensamento e ação, produzindo conhecimento e gerando novas indagações a respeito do tema pesquisado. Assim, o procedimento de compreensão da análise qualitativa dos dados colhidos no presente estudo seguiu um esquema de 10 (dez) passos, conforme exposto na Figura 1.

Figura 1- Análise qualitativa

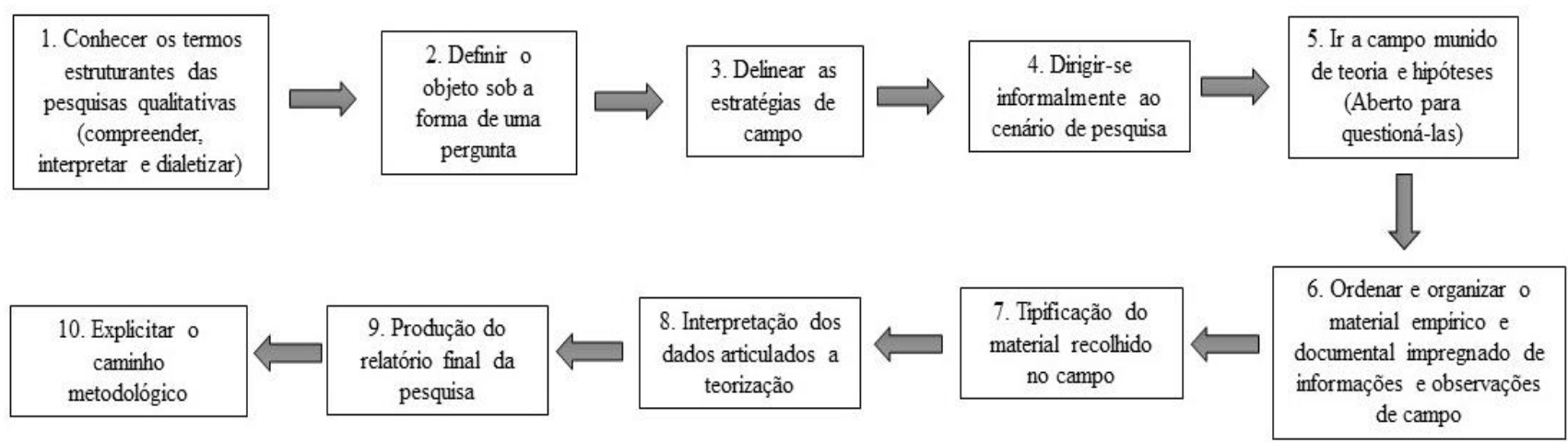

Fonte: Elaborada pela autora com base em Minayo (2012). 
Em seguida realizou-se a análise, ou seja, a compreensão e interpretação dos dados articulados ao marco teórico adotado no estudo, as informações adquiridas da análise documental, elaborando uma síntese com a apropriação das reflexões e interpretações acerca do objeto investigado.

\section{RESULTADOS E DISCUSSÕES}

Nesta seção é apresentada a análise dos dados coletados pela pesquisa em relação ao objeto de estudo. Inicialmente, apresenta-se os dados que tratam do perfil do discente retido do curso supracitado, descrito a partir de tabelas e feitas as referidas interlocuções com a realidade investigada. Na sequência são apresentados os resultados da análise global dos principais fatores associados à retenção escolar na percepção dos discentes do campus Cedro.

\subsection{Perfil dos discentes pesquisados}

As categorias abordadas na composição do perfil de discentes retidos foram o sexo, idade, raça/etnia/cor e renda mensal da família. Com relação aos participantes da pesquisa que responderam ao questionário no curso de Licenciatura em Matemática, 56,8\% dos respondentes eram do sexo feminino e $43,2 \%$ do sexo masculino. A opção "Não quero declarar o sexo" não foi assinalada por nenhum dos questionados.

Observa-se que no curso de Licenciatura em Matemática do campus Cedro, os discentes do sexo feminino representam maioria entre os alunos retidos. Nos estudos de Evangelista (2020) acerca da retenção discente no IFCE campus Maracanaú, a autora observou resultados semelhantes no curso Licenciatura em Química, que conta com o percentual 53,81\% de estudantes do sexo feminino.

Sobre a idade dos participantes da pesquisa, verifica-se que a maioria apresentou intervalo com variação de 18 a 24 anos, 59,5\% conforme exposto na Tabela 1. Constata-se que há predominância de jovens dentre os alunos em retenção no curso de licenciatura em questão, visto que esses dados revelam o ingresso dessa faixa etária pelo Ensino Superior (INEP, 2013).

Tabela 1- Percentual dos discentes retidos por faixa etária

\begin{tabular}{ccc}
\hline & & Percentual \\
\hline & 18 a 24 anos & $59,5 \%$ \\
\cline { 2 - 3 } Faixa etária & 30 a 29 anos 34 anos & $21,6 \%$ \\
\cline { 2 - 3 } & 35 a 39 anos & $2,7 \%$ \\
\cline { 2 - 3 } & 40 a 49 anos & $5,4 \%$ \\
\hline 50 anos ou mais & $8,1 \%$ \\
\hline
\end{tabular}

Fonte: Elaborado pela autora.

No que diz respeito à raça/cor/etnia, a maioria dos questionados se autodeclararam pardos, tal como apresentado na Tabela 2. De maneira adicional, em nenhuma dos cursos houve a marcação da opção "Não quero declarar". De acordo com dados da Pesquisa Nacional por Amostra de Domicílios (PNAD) 2019, a maioria dos brasileiros, $46,8 \%$ se declararam como pardos, $42,7 \%$ se declararam brancos, $9,4 \%$ como pretos e 1,1\% como amarelos ou indígenas. Essa predominância da categoria parda revelou-se no curso de licenciatura analisado nessa pesquisa, condizente com os resultados de 
Evangelista (2020), em que todos os cursos superiores analisados do IFCE campus Maracanaú, apresentaram essa mesma predominância nos estudantes retidos.

Tabela 2- Percentual dos discentes retidos por raça/etnia/cor

\begin{tabular}{ccc}
\hline & & Percentual \\
\hline & Preto & $16,2 \%$ \\
\cline { 2 - 3 } Raça/etnia/cor & Pardo & $64,9 \%$ \\
\cline { 2 - 3 } & Branco & $16,2 \%$ \\
\cline { 2 - 3 } & Amarelo & $2,7 \%$ \\
\cline { 2 - 3 } & Indígena & $0 \%$ \\
\hline
\end{tabular}

Fonte: Elaborado pela autora

Das opções elencadas sobre a renda mensal familiar dos estudantes na situação objeto do presente estudo, a maioria, 48,6\% afirmaram possuir rendimento familiar mensal da faixa de $\mathrm{R} \$ 522,50$ até $\mathrm{R} \$ 1045,00$. Assim, observou-se que a renda mensal familiar que teve maior incidência nos respondentes na Tabela 3 revelam a situação de vulnerabilidade socioeconômica dos discentes retidos que ingressam nos cursos ofertados pelos Institutos Federais. Essa realidade supracitada corrobora com os estudos de Silveira e Maraschin (2018, p.47) sobre o perfil do estudante do Instituto Federal Farroupilha (RS), estabelecendo possíveis conexões com os índices de evasão e retenção, afirmando que "esse dado demonstra as características socioeconômicas dos estudantes que acessam o IF Farroupilha, configurando em grande maioria de estudantes com famílias de baixa renda".

Tabela 3- Percentual dos discentes retidos por renda mensal familiar

\begin{tabular}{|c|c|c|}
\hline & & Percentual \\
\hline \multirow{7}{*}{$\begin{array}{l}\text { Renda } \\
\text { mensal } \\
\text { familiar }\end{array}$} & $\begin{array}{l}\text { Até } 1 / 4 \text { do salário-mínimo } R \$ \\
261,25\end{array}$ & $5,4 \%$ \\
\hline & $\begin{array}{l}\text { Superior a } 1 / 4 \text { do salário-mínimo } \\
\operatorname{R} \$ 261,25\end{array}$ & $24,4 \%$ \\
\hline & $\begin{array}{l}\text { Superior a } 1 / 2 \text { salário-mínimo } \\
R \$ 522,50 \text { até } 1 \text { salário-mínimo } R \$ \\
1045,00\end{array}$ & $48,6 \%$ \\
\hline & $\begin{array}{l}\text { Superior a } 1 \text { salário-mínimo } \mathrm{R} \$ \\
1045,00 \text { até } 2 \text { salários-mínimos } \\
\mathrm{R} \$ 2090,00\end{array}$ & $5,4 \%$ \\
\hline & $\begin{array}{l}\text { Mais de dois salários-mínimos } \mathrm{R} \$ \\
2090,00\end{array}$ & $10,8 \%$ \\
\hline & Não possui renda & $5,4 \%$ \\
\hline & $\begin{array}{l}\text { Renda familiar advinda de } \\
\text { programas sociais. }\end{array}$ & $0 \%$ \\
\hline
\end{tabular}

Portanto, a análise dos aspectos relativos ao perfil do estudante em situação de retenção pode colaborar para a formulação de estratégias para minimizar a problemática na instituição de ensino, inclusive nos Institutos Federais. Segundo Pereira (2013, p. 80), a análise do perfil do estudante retido pode "subsidiar o planejamento e elaboração de políticas e programas com o objetivo de 
melhorar as condições de formação dos alunos e reduzir os níveis de retenção na instituição". Sendo também necessária a análise dos fatores associados à retenção discente que perpassam a formação desses estudantes e interferem em sua trajetória acadêmica.

\section{5 .2 Fatores determinantes da retenção escolar na percepção dos discentes}

A análise global dos fatores associados à retenção dos estudantes do curso de Licenciatura em Matemática será apresentada através das categorias: as causas da retenção escolar no seu curso; principal motivo de sua retenção escolar e não conclusão do curso e principal dificuldade para conclusão do curso.

Inicialmente verificou-se sobre as principais causas da retenção escolar no curso, onde mais de uma opção poderia ser marcada pelos alunos, como também, abrimos espaço para que expusessem outras causas que não constavam na lista de opções. Das respostas apresentadas nos questionários, houve o predomínio das causas problemas pessoais, familiares e sociais, e excessivas reprovações nas disciplinas, ambas apresentando o percentual de $54,1 \%$. Os dados do curso estão detalhados no Quadro 2 a seguir.

Quadro 2- Causas da retenção escolar na percepção dos discentes retidos

\begin{tabular}{|l|c|}
\hline \multicolumn{1}{|c|}{ Causas da retenção escolar } & $\begin{array}{c}\text { Percentua } \\
\text { I }\end{array}$ \\
\hline Problemas pessoais, familiares e sociais & $54,1 \%$ \\
\hline Excessivas reprovações nas disciplinas & $54,1 \%$ \\
\hline Déficit de aprendizagem dos estudantes nas disciplinas & $48,6 \%$ \\
\hline Metodologia dos professores & $32,4 \%$ \\
\hline $\begin{array}{l}\text { Questões psicológicas e de adoecimento mental dos } \\
\text { estudantes }\end{array}$ & $27 \%$ \\
\hline Dificuldade de adaptação à vida acadêmica & $24,3 \%$ \\
\hline Falta de ações preventivas quanto à retenção e evasão & $16,2 \%$ \\
\hline $\begin{array}{l}\text { Auxílios estudantis financeiros insuficientes para atender a } \\
\text { demanda de todos os estudantes que necessitam }\end{array}$ & $16,2 \%$ \\
\hline Relação entre professor e aluno & $10,8 \%$ \\
\hline Outros & $10,8 \%$ \\
\hline Acompanhamento pedagógico e multidisciplinar frágil & $8,1 \%$ \\
\hline Infraestrutura física, material e tecnológica & $2,7 \%$ \\
\hline
\end{tabular}

Fonte: Elaborado pela autora.

Na percepção dos discentes predominaram os problemas pessoais, familiares e sociais e excessivas reprovações nas disciplinas, obtendo-se o mesmo percentual $(54,1 \%)$. Nesse mesmo curso, a causa déficit de aprendizagem dos estudantes nas disciplinas teve um número significativo (48,6\%). Segundo Rios et al. (2018, p.36), em seus estudos com retenção, constataram que a maioria dos alunos têm reprovações por nota e/ou faltas, e que dentre as motivações para a reprovação, destacam-se entre os estudantes as dificuldades didático-pedagógicas com referência aos currículos 
dos cursos, professores, e ainda salientam que "a reprovação pode implicar em retenção e posteriormente na evasão e ambas as situações causam danos ao estudante e a sociedade".

Buscando aprofundar um pouco mais sobre a temática dessa pesquisa, os estudantes foram questionados acerca do principal motivo da retenção escolar e não conclusão do curso, conforme apresentado no Gráfico 1. Adicionalmente foi disposto a opção "outros", para aqueles que não se sentissem contemplados nos motivos elencados e se desejassem, podiam expor outros motivos.

\section{Gráfico 1 - Motivos de retenção e não conclusão do curso}

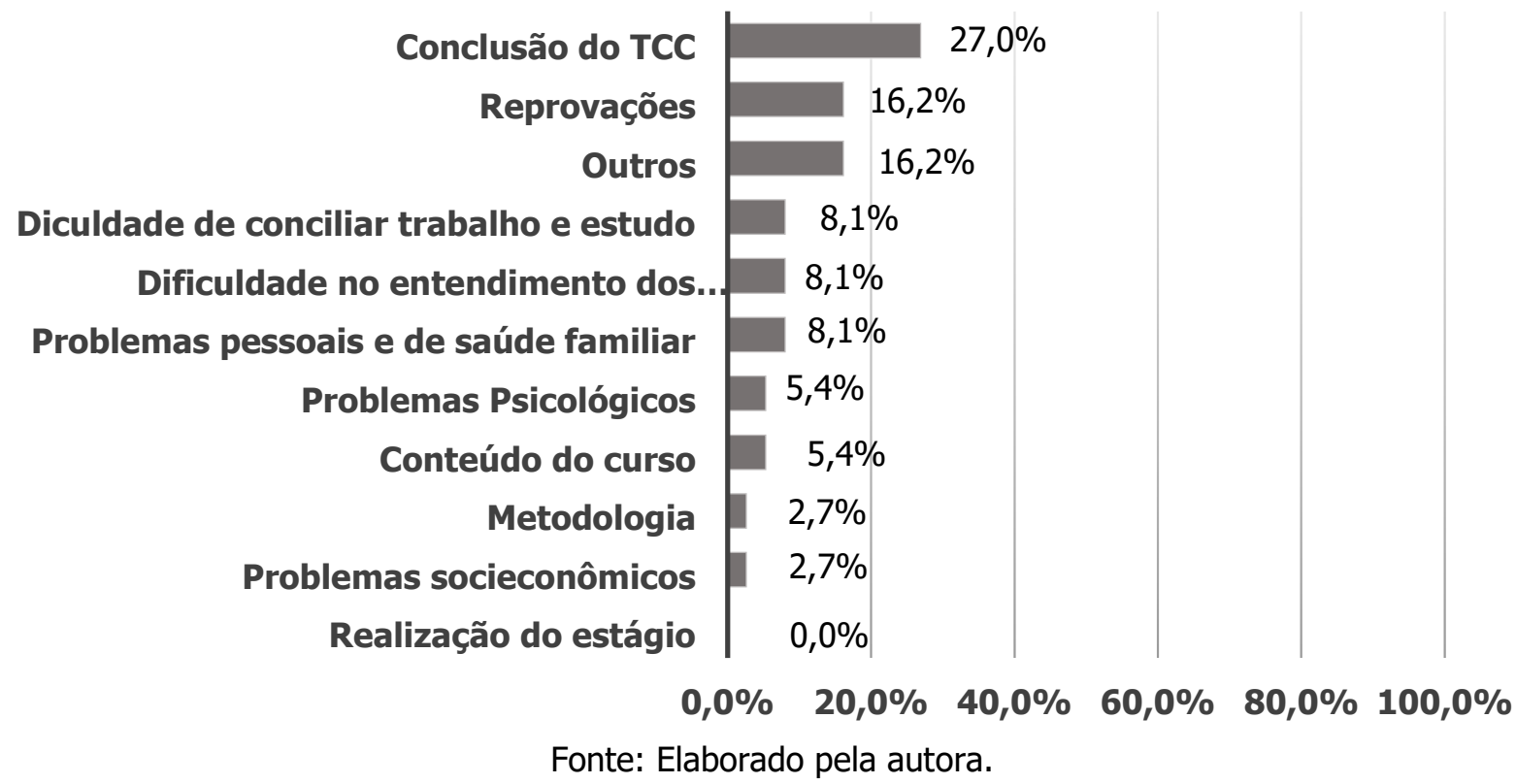

Percebe-se que o motivo que prevaleceu foi a conclusão do Trabalho de Conclusão de Curso (TCC), e ainda alguns estudantes se expressaram na opção outros e afirmaram que há a dificuldade em escrever a monografia, como também, o cansaço psicológico seguido de desmotivação em escrever o TCC.

No entanto, diante das respostas que foram apresentadas pelos questionados, pôde-se verificar que esse dado majoritário sobre a conclusão do TCC ser o principal motivo dos estudantes retidos da Matemática, provavelmente está ligado a dinâmica do processo de pesquisa, ao tempo de coleta e análise dos dados, tornando-se inviável viabilizar em um semestre, bem como, a dificuldade envolvida para desenvolvimento desse processo por parte do aluno e orientação do professor. Semelhantemente ao que descreve Morais (2015) que

deve-se ter em mente que quer seja por motivos pessoais, pela falta de tempo disponível ou até pelas dificuldades com a pesquisa, o TCC demonstra um potencial de retenção do alunado que deve ser considerado pela instituição. Essa deve elaborar com cuidado a grade de disciplinas do final da graduação, já prevendo a necessidade da revisão bibliográfica e da pesquisa de campo e, ainda, preparar o estudante para essa fase, com orientações a respeito do desenvolvimento do TCC e de como organizar tempo, realizar a pesquisa, entre outras necessidades apresentadas. (MORAIS, 2015, p.72) 
Em outra pergunta, buscou-se verificar qual a principal dificuldade que os estudantes do Campus Cedro têm enfrentado para concluir seu curso na percepção dos alunos retidos do curso em análise (Quadro 3) ${ }^{10}$ predominaram as dificuldades relacionadas às excessivas reprovações nas disciplinas do curso $(59,5 \%)$.

Quadro 3- Dificuldades para conclusão do curso na percepção dos discentes retidos

\begin{tabular}{|l|c|}
\hline \multicolumn{1}{|c|}{ Dificuldades } & Percentual \\
\hline Excessivas reprovações nas disciplinas do curso & $59,5 \%$ \\
\hline Trabalho de conclusão de curso, estágio & $48,6 \%$ \\
\hline Desmotivação para concluir o curso & $48,6 \%$ \\
\hline $\begin{array}{l}\text { Dificuldades de aprendizagem com as matérias e conteúdos } \\
\text { ministrados. }\end{array}$ & $43,2 \%$ \\
\hline $\begin{array}{l}\text { Dificuldades com a metodologia dos professores, relação professor } \\
\text { aluno }\end{array}$ & $45,9 \%$ \\
\hline Dificuldade de conciliar trabalho e estudo & $37,8 \%$ \\
\hline Dificuldades financeiras & $29,7 \%$ \\
\hline Dificuldade de deslocamento para a instituição & $24,3 \%$ \\
\hline Problemas psicológicos & $16,2 \%$ \\
\hline $\begin{array}{l}\text { Falta de acompanhamento e incentivo da instituição para reduzir a } \\
\text { retenção dos estudantes }\end{array}$ & $13,5 \%$ \\
\hline $\begin{array}{l}\text { Falta de ações de intervenção com os estudantes retidos e que não } \\
\text { concluíram o curso }\end{array}$ & $13,5 \%$ \\
\hline Outros & $5,4 \%$ \\
\hline
\end{tabular}

Fonte: Elaborado pela autora.

Verificou-se que a dificuldade relacionada às excessivas reprovações nas disciplinas do curso foi a mais apontada entre os respondentes, sendo igualmente apontada como uma das causas da retenção e da mesma forma verificada na análise documental nos históricos escolares. Salienta-se ainda a desmotivação para concluir o curso e o trabalho de conclusão de curso, estágio, apresentaram percentual significativo entre as dificuldades escolhidas entre os questionados do curso $(48,6 \%)$.

Os referidos resultados também foram demonstrados por Pereira (2013) em seu estudo com alunos retidos dos cursos superiores de graduação da Universidade Federal do Espírito Santo (UFES), no qual elencou o número de reprovações como um dos fatores relevantes no processo de retenção. Portanto, uma alternativa seria a centralidade das ações institucionais na melhoria do desempenho acadêmico dos discentes e a na busca por metodologias que trabalhem de maneira interdisciplinar os conteúdos.

\footnotetext{
${ }^{10}$ Mais de uma opção poderia ser marcada nesta pergunta do questionário, bem como, foi disposto a opção "outros".
} 
De maneira adicional, nessa pergunta, mais de uma opção poderia ser marcada, bem como foi ofertado a opção outros e comentaram que as dificuldades também envolvem falta compreensão dos profissionais que levam a constrangimento e, que o período de 4 anos não é suficiente para boa parte dos alunos concluírem o curso, pois o Ensino Superior exige uma maior preparação por parte dos estudantes que acabaram de sair do ensino médio, frente às demandas da vida acadêmica.

Dessa forma, a retenção tem relação com a forma que o aluno aprende, a sua relação com saber, e muitos são os fatores que se associam a ocorrência desse fenômeno, configurando-se como obstáculos ao percurso formativo desses estudantes. Segundo Libâneo (2013, p.88), a aprendizagem escolar "é um processo de assimilação de determinados conhecimentos e modos de ação física e mental, organizados e orientados no processo de ensino".

\section{CONSIDERAÇÕES FINAIS}

A expansão dos Institutos Federais possibilitou a interiorização e ampliação da oferta de educação profissional e acesso ao ensino público. Porém, foram destacadas as problemáticas dos índices elevados de retenção, apontando para o desafio de garantia da permanência e êxito dos alunos nessas instituições.

Nesse contexto, a retenção escolar apresenta-se como um fenômeno presente no âmbito educacional, inclusive nos Institutos Federais, sendo uma problemática que interfere na formação acadêmica, podendo levar o estudante a não concluir sua formação e ainda a uma possível evasão.

Entre os resultados encontrados por meio da análise dos dados coletados na primeira parte do questionário, observou-se que os estudantes retidos do curso de Licenciatura em Matemática da instituição tinham, em sua maioria, as seguintes características: pertencentes ao sexo feminino; inseridos na faixa de idade 18 a 24 anos; raça/cor/etnia parda e renda familiar mensal superior a $1 / 2$ salário até 1 salário-mínimo.

Quanto à análise dos dados coletados em referência aos fatores determinantes para retenção foram os relacionados ao déficit de aprendizagem dos estudantes nas disciplinas; as dificuldades de aprendizagem com as matérias e conteúdos ministrados; os problemas pessoais, familiares e sociais; as excessivas reprovações nas disciplinas; a finalização do Trabalho de Conclusão de Curso e a desmotivação para concluir o curso.

Assim, constatou-se com o presente trabalho que a retenção se apresenta como uma problemática complexa existente nos diversos níveis e modalidades de ensino, não sendo possível apontar um único fator determinante para ocorrência do fenômeno, tendo origem nos diversos fatores individuais dos estudantes, internos e externos ao ambiente institucional, sendo necessário a elaboração de estratégias para o desenvolvimento de ações para prevenção e acompanhamento dos estudantes retidos tais como diagnóstico e apoio ao processo de aprendizagem dos estudantes; acompanhamento e prevenção de discentes com reprovações; acompanhamento de discentes em conclusão de curso e estágio; suporte à formação acadêmica do discente e acolhimento e integração à rotina acadêmica. 


\section{REFERÊNCIAS}

BRASIL. Lei 11.892 de 29 de dezembro de 2008. Institui a Rede Federal de Educação Profissional, Científica e Tecnológica, cria os Institutos Federais de Educação, Ciência e Tecnologia, e dá outras providências. Diário Oficial [da] República Federativa do Brasil, Brasília, DF, 29 dez. 2008. [online]. Disponível em: http://www.planalto.gov.br/ccivil_03/_Ato20072010/2008/Lei/L11892.htm. Acesso em: 21 de jan. 2020.

BRASIL. Ministério da Educação. Diplomação, retenção e evasão nos cursos de graduação em instituições de ensino superior públicas. Brasília (DF): Ministério da Educação, 1996. [online]. Disponível em: http://periodicos.uniso.br/ojs/index.php/avaliacao/article/view/739. Acesso em: 10 de nov. 2019.

BRASIL. Ministério da Educação. Documento orientador para a superação da evasão e retenção na Rede Federal de Educação Profissional, Científica e Tecnológica. MEC/SETEC, Brasília, 2014. [online]. Disponível em http://r1.ufrrj.br/ctur/wpcontent/uploads/2017/03/Documento-Orientador-SETEC.pdf. Acesso em 12 de abr. 2020.

BRASIL. Plataforma Nilo Peçanha. Ano base 2019. Brasília (DF): Ministério da Educação, 2020. [online]. Disponível em: http://plataformanilopecanha.mec.gov.br/. Acesso em: 02 de mai. 2020.

BRASIL. Tribunal de Contas da União. Relatório de Auditoria. 2012. [online]. Disponível em: http://portal.tcu.gov.br/lumis/portal/file/fileDownload.jsp?inline=1\&fileId=8A8182A14D92792C014D 92847E5F3E97. Acesso em: 01 de dez. 2019.

DAITX, André Cristo; LOGUERCIO, Rochele de Quadros; STRACK, Ricardo. Evasão e retenção escolar no curso de licenciatura em química do instituto de química da UFRGS. Investigações em Ensino de Ciências - v 21 (2), p. 153-178, 2016. [online]. Disponível em:

https://www.if.ufrgs.br/cref/ojs/index.php/ienci/article/view/111. Acesso em: 01 de dez. 2019.

DORE, Rosemary; LÜSCHER, Ana Zuleima. Permanência e evasão na educação técnica de nível médio em Minas Gerais. Cadernos de Pesquisa, v. 41, n. 144, p. 770-89, dez. 2011. [online]. Disponível em: https://www.scielo.br/pdf/cp/v41n144/v41n144a07.pdf. Acesso em: Acesso em: 01 de dez. 2019.

EVANGELISTA, Leiliane Lima Almeida. Retenção discente em cursos de graduação: um estudo no Instituto Federal de Educação, Ciência e Tecnologia. Dissertação (Mestrado Profissional em Políticas Públicas e Gestão do Ensino Superior) - Universidade Federal do Ceará, Fortaleza, 2020.

GAIOSO, Natalicia Pacheco de Lacerda. O fenômeno da evasão escolar na educação superior no Brasil. Dissertação (Mestrado em Educação) -Universidade Católica de Brasília, Brasília, 2005.

IBGE. Pesquisa Nacional por Amostra de Domicílios (PNAD) 2019. [online]. Disponível em: https://educa.ibge.gov.br/jovens/conheca-o-brasil/populacao/18319-cor-ou-raca.html Acesso em: 20 de jan 2021.

IFCE. IFCE em números. Fortaleza: IFCE, 2016. [online]. Disponível em: http://ifceemnumeros.ifce.edu.br/. Acesso em: 20 de jan. 2021.

IFCE. Plano estratégico para permanência e êxito dos estudantes do IFCE. Fortaleza: IFCE, 2017. [online]. Disponível em https://ifce.edu.br/proen/ensino/plano-de-permanencia-e-exito.pdf . Acesso em 22 de mai. 2020. 
INEP. Relatório Censo da Educação Superior 2013. Instituto Nacional de Estudos e Pesquisas Educacionais Anísio Teixeira. [online]. Disponível em: http://portal.inep.gov.br/web/ censo-daeducacao-superior. Acesso em: 03 de maio de 2020.

LIBÂNEO, José Carlos. Didática. 2 ed. São Paulo: Cortez, 2013.

LIMA, Lílian Martins de. O perfil da retenção nos cursos técnicos integrados ao ensino médio do Campus São Paulo (2014-2017): um estudo preliminar. IV Congresso de Educação Profissional e Tecnológica - CONEPT. Araraquara, 2018.

MARTINHO, Mailson; COSTA, Edna Maria Mendes Pinheiro; GOMES, Vera Rejane; OLIVEIRA, Lueny Amorim de; LIMA, Maria de Lourdes Silva. Retenção no ensino médio: problemáticas e consequências. Braz. J. of Develop., Curitiba, v. 5, n. 4, 2019. [online]. Disponível em: https://www.brazilianjournals.com/index.php/BRJD/article/view/1496\#: :text=A\%20reten\%C3\%A 7\%C3\%A3o\%20\%C3\%A9\%20um\%20acontecimento,n\%C3\%ADveis\%20e\%20modalidades\%20de $\% 20$ ensino. Acesso em: 22 de mai. 2020.

MEC. Rede Federal de Educação Profissional, Científica e Tecnológica. Brasília: 2021. [online]. Disponível em: http://portal.mec.gov.br/rede-federal-inicial. Acesso em: 14 de maio de 2021.

MELO, Ana Danielle de Queiroz; SALDANHA, Sabrina Maria Cordeiro. A retenção dos alunos da Licenciatura em Química do IFCE, campus Quixadá: uma análise. Educação, Escola e Sociedade, v. 13, 2020. [online]. Disponível em:

https://www.periodicos.unimontes.br/index.php/rees/article/view/1980. Acesso em: 22 de maio. 2020.

MINAYO, Cecília de Sousa. Pesquisa Social: teoria, método e criatividade. 26 ed, Petrópolis, RJ: Editora Vozes, 2009.

MINAYO, Cecília de Sousa. Análise qualitativa: teoria, passos e fidedignidade. Ciência \& Saúde Coletiva, v.17(3), p.621-626, 2012. [online]. Disponível em:

https://www.scielo.br/j/csc/a/39YW8sMQhNzG5NmpGBtNMFf/?lang=pt. Acesso em: 22 de mai. 2020.

OLIVEIRA, Flávia Alves de Castro. Evasão no ensino Técnico Profissionalizante: um estudo de caso no Instituto Federal Goiano- Campus Ceres. Dissertação (Mestrado Profissional em Educação Profissional e Tecnológica), Instituto Federal Goiano, Morrinhos, 2019.

PEREIRA, Alexandre Severino. Retenção discente nos cursos de graduação presencial da UFES. Dissertação (Mestrado Profissional em Gestão Pública) - Universidade Federal do Espírito Santo, Vitória, 2013.

RIOS, Rafaela; COSTA, Vânia Medianeira Flores; BIANCHIM, Bruna de Vargas; SANTOS, Rita de Cássia Trindade dos; Rodrigues, Aline Mendonça. Evasão, retenção e diplomação: ocorrências e motivações. Revista GUAL, Florianópolis, v. 11, n. 4, p. 20-39, Edição Especial 2018. [online]. Disponível em: https://periodicos.ufsc.br/index.php/gual/article/view/1983-4535.2018v11n4p20. Acesso em: 01 de dez. 2019.

ROSA, Alcemir Horácio. Ecos da EPT- a evasão escolar nos cursos técnicos: diagnóstico, números e propostas para o fortalecimento do ensino técnico- Um estudo de caso sobre a realidade do IFPI Parnaíba. Dissertação (Mestrado Profissional de Educação Profissional e Tecnológica), IFCE, Fortaleza, 2019. 
MORAES, Joana de Paula Boeno. Retenção discente no centro de ciências humanas e naturais da UFES: o caso do curso de letras-português e geografia. Dissertação (Mestrado em Gestão Pública) - Universidade Federal do Espírito Santo, Vitória, 2015.

SANTOS, Thiago Silva dos; MEDEIROS, Claudia Silva; VALLERIUS, Daniel Mallmann. "O que a escola (re)prova?" - algumas considerações sobre a reprovação escolar. Vi. En. (Online), v.3, n.1, p. 117-131, Iporá, set./dez. 2017. [online]. Disponível em: https://periodicos.ifgoiano.edu.br/. Acesso em: 01 de dez. 2019.

SILVA, Francisca Islândia Cardoso da; RODRIGUES, Janete de Páscoa.; BRITO, Ahécio Kleber Araújo. Retenção escolar no curso de Educação física da Universidade Federal do Piauí. Educação em Perspectiva, Viçosa, v. 5, n. 2, p. 75-96, jul./dez. 2014. [online]. Disponível em: https://periodicos.ufv.br/educacaoemperspectiva/article/view/6661. Acesso em: 01 de dez. 2019.

SILVEIRA, Rozieli Bovolini; MARASCHIN, Mariglei Severo. A Educação Profissional e Tecnológica e as relações da evasão e da retenção: uma análise do perfil do estudante. Tecnia, v.3, n.2, 2018. [online]. Disponível em: http://revistas.ifg.edu.br/tecnia/article/view/247. Acesso em: 10 de jun. 2020.

Submissão: 01/06/2021

Aceito: 01/07/2021 